\title{
THERMAL BEHAVIOUR OF EXPANDED POLYSTYRENE BASED LIGHTWEIGHT CONCRETE SANDWICH PANEL AT VARIOUS TEMPERATURES
}

\author{
Surya Man Koju \\ Department of Electronics Engineering, Khwopa Engineering College, Libali-8, Bhaktapur, Nepal
}

\begin{abstract}
Expanded Polystyrene (EPS) based lightweight concrete sandwich panel is a light weight building material that exhibits good thermal properties and is suitable for making thermally insulated building walls. This study contains experimental determination of thermal conductivity, overall heat transfer coefficient and thermal resistance of EPS based lightweight concrete sandwich panels. Resistive heating is used for performing thermal tests. Internal heat transfer is considered during experiment and the results are achieved by steady state heat transfer method. Thermal quality of sandwich panel with varying thicknesses is observed. Experiments are repeated with four types of source temperatures. All the samples are oven dried before taken into experimentation. The thermal results indicated that EPS based lightweight concrete sandwich panel poses overall heat transfer coefficient of $1.75 \mathrm{~W} / \mathrm{m}^{2} \mathrm{~K}, 2.06 \mathrm{~W} / \mathrm{m}^{2} \mathrm{~K}, 6.09 \mathrm{~W} / \mathrm{m}^{2} \mathrm{~K}$ and $6.54 \mathrm{~W} / \mathrm{m}^{2} \mathrm{~K}$ for $90 \mathrm{~mm}$ thick sandwich panel at low temperature, ambient temperature, high temperature and extreme temperature respectively.
\end{abstract}

Keywords: Coefficient of thermal conductivity, light weight concrete, steady state heat transfer, EPS.

\section{Introduction}

The interest for light-weight concrete in modern construction applications, such as high rise buildings, offshore structures and long span bridges is rising (Ning \& Bing, 2014). This is due to decreasing volume of many load bearing elements, as well as superior thermal properties of lightweight compared to conventional concrete and building bricks. From an economic and environmental conservation point of view, it is more beneficial to design buildings with high thermal insulation characteristics than the old practice currently followed in the construction of buildings (Oluwole, Joshua, \& Nwagwo, 2012).Foam concrete has been widely used in non-structural applications. It is basically understood that as the density of lightweight concrete decreases, its thermal insulation would increase.

\footnotetext{
*Corresponding author: Surya Man Koju

Department of Electronics Engineering, Khwopa Engineering College, Libali-8, Bhaktapur, Nepal

Email: koju.surya@gmail.com

(Received: 2016 Nov 10 Accepted:2016 Dec 07)
}

Thermal behavior of any material is characterized by its thermal conductivity, overall heat transfer coefficient and thermal resistance. These parameters have dependency, however, on source temperature. Overall heat transfer should be such that it maintains comfort temperature (Koju, 2015). Although coefficient of thermal conductivity and overall heat transfer coefficients are material property, it depends upon temperature of the source. Different temperature environments has different effect on thermal behavior. In the class of light-weight concrete Expanded Polystyrene based panel is one of the lightest composites and it weight up to several times less than the weight of similar materials (Panjehpour, 2014). By using it for partition walls, insulation of the building can be assured as well as the load carried by structural members becomes considerably reduced. In either cases, cost or energy consumption is considerably reduced. With former aspect of insulation of building, cost for extra thermal insulation other than from infill walls is reduced as lightweight materials are known for better insulation. Also, energy consumed during space heating and space cooling is reduced by reducing the operating time of appliances that is used for these purposes. With later aspect of 
reduction of dead load, structural cost is minimized and in addition to that daily operating cost is also minimized due to quick erection and fast installation works of the panels.

Because of the finite supply of fossil fuels and the high cost of energy, the need to design energyefficient buildings that are also economical becomes important (Leila \& Nacerddine, 2013). Various industry groups are continually updating and refining energy conservation standards and guidelines for use in the design of new buildings. These standards and guidelines may be used to assist the building designers. The designer is confronted with the fact that no two buildings are exactly identical, nor are the methods or modes of operation similar. Thus, the energy performance of each building, as a whole, must be evaluated relative to the real performance of its materials, systems and equipment (Braz, 2012).

Today, thermal insulation has become one of the major aspects in modern buildings. Quality of building material is also being measured by its aesthetic value. Thermally insulated building provides comfort temperature. Thermal energy absorbed by building surface at day time can be utilized at appropriate time when required. For this, building materials should have appropriate thermal inertia. With smart choice of building material composition, these building materials can act as "Thermal Capacitors" that stores thermal energy from the daylight when available and it passes through it inside the building when required.

Remarkable amount of energy is being used for space heating and space cooling inside buildings. In the context of Nepal, people at Himali region use heating equipment for space heating, and people at Terai region use cooling equipment for space cooling. Thermally more insulated buildings reduce this kind of energy consumption. In addition, this consumed energy is generated energy, and the equipment used for space heating or space cooling may not have cent percent efficiencies.

Thermal behavior of isotropic material is easy to obtain. However, thermal conductivity of insulators cannot be obtained by methods used for thermal conductors. The steady-state measurement techniques are based on establishing a temperature gradient over a known thickness of a sample to control the heat flow from one side to the other. A one-dimensional flow approach has been employed most frequently, but also other geometrical arrangements are used. The thermal conductivity is simply determined by measuring the temperature gradient and the heat flow through the sample. Most commonly used is steady-state measurement. The steady-state measurement techniques are based on establishing a temperature gradient over a known thickness of a sample to control the heat flow from one side to the other. A one-dimensional flow approach has been employed most frequently, but also other geometrical arrangements are used. The thermal conductivity is simply determined by measuring the temperature gradient and the heat flow through the sample.

Another crucial fact is that thermal behavior of material is not just a material property. The source temperature is also a fundamental parameter in thermal behavior. Higher the source temperature higher the value of overall heat transfer coefficient. However, remarkable change is seen only at certain range of temperatures. These temperature ranges can be named as below room temperature, room temperature, high temperature and extreme temperature. Thermal conductivity is the property that determines the working temperature levels of a material. It assumes a critical role in the performance of materials, and it is important parameter in problems involving steady state heat transfer. It is one of the physical quantities whose measurement is very difficult, and it requires high precision in the determination of the factors necessary for its calculation. The knowledge of thermal conductivity and other thermal transport properties of construction materials is involved in the process of modeling heat transfer profile and heat flow through the material. Effective thermal conductivity is the net overall thermal conductivity of porous materials. Its prediction is not a straight forward process. This turns out to be difficult problem because the transfer property is a complex function of many other parameters, such as the thermal conductivities of each phase, their relative proportions, and the size of the solid particles, the contact areas and distribution within the medium. 
Thermal behavior of prefabricated panels depends on thickness as well as composition of the materials used in the panels. Thermal conduction varies due to different composition of materials (Koju, 2015).

Lightweight concrete panel is however non-load bearing and can be only used as partition wall in frame structure. Since most of heat gain or loss in building occurs via these infill walls, high thermal insulation of these walls is desirable. Lightweight concrete panel, a prefabricated panel, might be a solution.

In this work, thermal conductivity of EPS based lightweight concrete panel has been determined by means of steady state heat transfer method. It is a technique which measures temperature gradient and heat flux at steady state. Resistive heater generates heat energy which has 100 percent heat efficiency. Steady state heat flow analysis can be used to study thermal behavior of high insulation building materials. It can also be used to determine overall heat transfer coefficient and thermal resistance of the building material. Constant temperature gradient of two ends of the specimen indicates steady state of the heat transfer mechanism. Cooling agents can be used to increase the heat transfer rate.

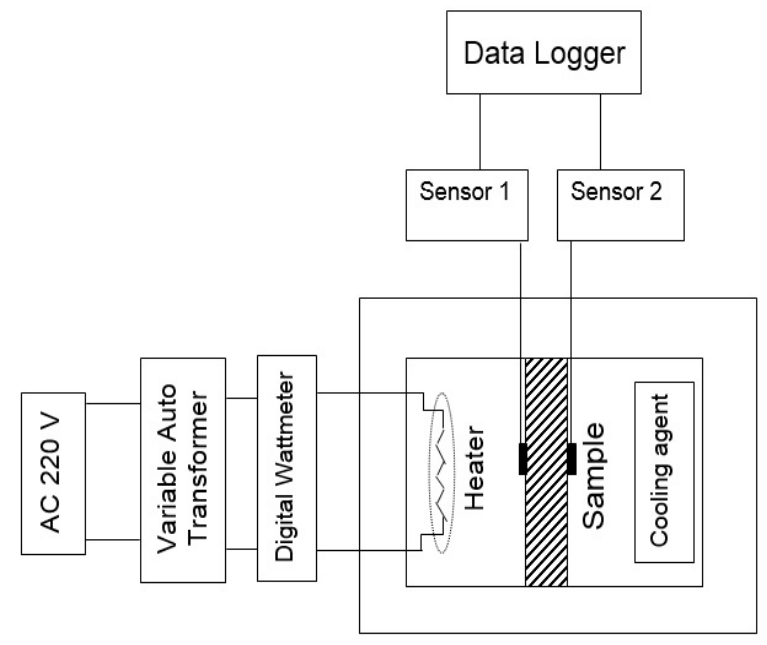

Fig 1 Schematic diagram of experimental setup

\section{Experimental Setup}

The numerical study of thermal conductivity values of the sandwich panel and common brick under steady state condition is done using an experimental set up as shown in Fig. 1. All of the inner side surfaces of hot box except right side wall are insulated with $5 \mathrm{~cm}$ of thermocol to prevent ambient heat loss. Heat is generated by using electrical resistive heater. Energy is supplied by controlled AC power supply system. Sensitivity of temperature measurement is $0.5^{\circ} \mathrm{C}$. Temperature is measured continuously by temperature sensors and recorded in SD-Card via Data logger. Steady state condition and temperature values at that condition are analyzed using spreadsheet. Temperature in range from $10^{\circ} \mathrm{C}$ to $20^{\circ} \mathrm{C}$ is below room temperature which has been considered as low temperature in this experimentation. Temperature in range from $25^{\circ} \mathrm{C}$ to $40^{\circ} \mathrm{Cis}$ ambient temperature which has been considered as normal temperature. Temperature that lies between $50^{\circ} \mathrm{C}$ and $70^{\circ} \mathrm{C}$ is high temperature and temperature that is in between $90^{\circ} \mathrm{C}$ and $110^{\circ} \mathrm{C}$ is called as extreme temperature in this experimentation. Samples are prepared by cutting them in proper dimensions with surface cross section area in the direction of heat flow of approximately 0.4 square meter.

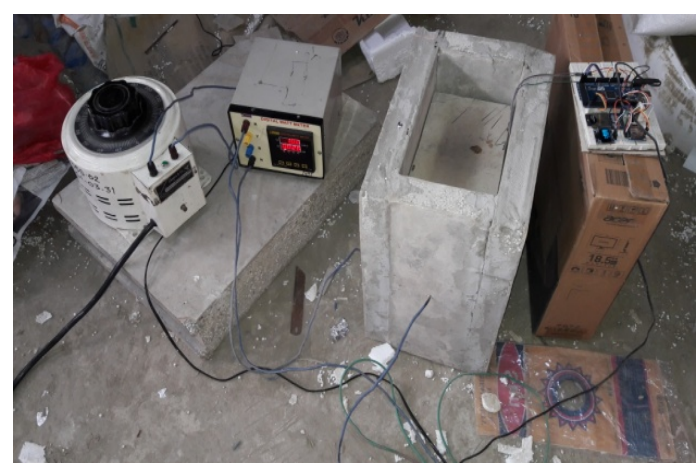

Fig 2 Experimental setup connection for thermal tests of sandwich panel 
The numerical study gives thermal conductivity values, overall heat transfer (U-values) and thermal resistance (R) values of EPS panel and common brick.

$\mathrm{k}=\frac{\mathrm{QXL}}{\mathrm{AX \Delta T}}$, in $\mathrm{W} /(\mathrm{m} \cdot \mathrm{K})$

$\mathrm{U}=\mathrm{q} / \Delta \mathrm{T}$, in $\mathrm{W} /\left(\mathrm{m}^{2} \cdot \mathrm{K}\right)$

$\mathrm{R}=\mathrm{A} \times \Delta \mathrm{T} / \mathrm{Q}$, in $\left(\mathrm{m}^{2} \cdot \mathrm{K}\right) / \mathrm{W}$

where,

$\mathrm{Q}=$ heat transfer rate $(\mathrm{W})$,

$\mathrm{q}=$ heat flux $\left(\mathrm{W} / \mathrm{m}^{2}\right)$,

$\mathrm{L}=$ Thickness of the panel (m),

$\mathrm{A}=$ Surface Area of the panel $\left(\mathrm{m}^{2}\right)$,

$\Delta \mathrm{T}=$ Temperature Gradient $(\mathrm{K})$

(O'Connell, 2005)

Overall heat transfer coefficient, thermal conductivity and thermal resistance values of EPS based lightweight panel of different thickness were compared with each other. Overall heat transfer coefficient of panel with same thickness was experimented for four different temperature range. Panel thickness of $50 \mathrm{~mm}, 60 \mathrm{~mm}, 75 \mathrm{~mm}$, $90 \mathrm{~mm}, 120 \mathrm{~mm}$ and $150 \mathrm{~mm}$ were taken under study.

\section{Result and Discussion}

The source temperature was varied to different values that represented various range to temperature such as below room or low temperature, room temperature, high temperature and extreme temperature. It is found that thermal conductivity of EPS based lightweight panel increases with increase in temperature range. Also thermal conductivity of the panel is approximately three times better than common building brick when thermal insulation is of concern. Overall heat transfer coefficient decreases as thickness of the panel increases. However, with increase in source temperature the overall heat transfer coefficient also increases, considerably at different range. Steady state condition was achieved after few hours but experiments were continuously performed for 10 to 12 hours to obtain exact nature of curve.

\subsection{Thermal Behavior Tests}

Fig 3 - Fig 5 show the thermal conductivity, overall heat transfer coefficient and thermal resistance values of the panel of various thickness at various temperature. Thermal conductivity slightly increases for thicker samples. But, thermal conductivity value is greatly influenced by source temperature. Thermal Conductivity of Sandwich panel is $0.14 \mathrm{~W} /(\mathrm{m} . \mathrm{K})$ at room temperature whereas it is $0.42 \mathrm{~W} /(\mathrm{m} . \mathrm{K})$ for solid part of building brick (SaitSoylemez, 1998). Thermal resistance value is nearly unity at room temperature which is comparable to the thermal resistance of EPS Wall Panels as it is 1.4 $\left(\mathrm{m}^{2} . \mathrm{K}\right) / \mathrm{W}$ (Ede \& Ogundiran, 2014). But, thermal resistance is decreased when the source temperature is increased. Thermal resistance has increased when the panel thickness has increased.

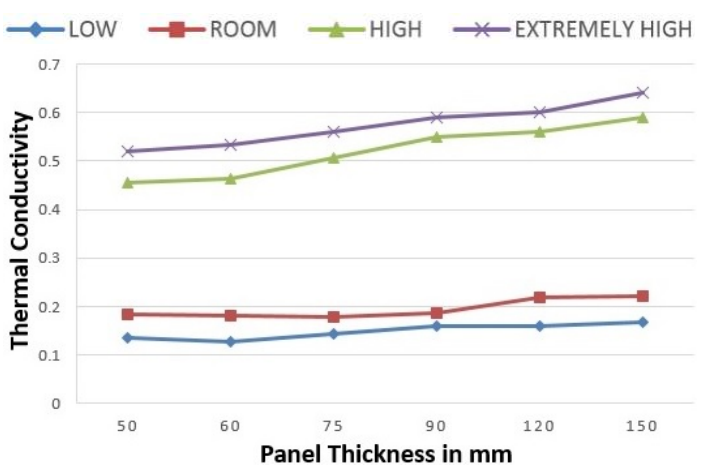

Fig 3 Thermal conductivity (in W/m.K) values of sandwich panel of various thickness at various temperature

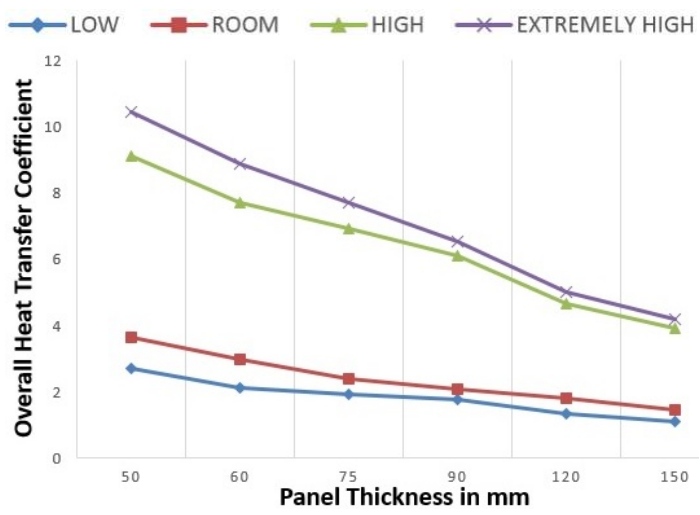

Fig 4 Overall Heat transfer coefficient (in $\mathrm{W} / \mathrm{m}^{2} . \mathrm{K}$ ) of sandwich panel of various thickness at various temperature 


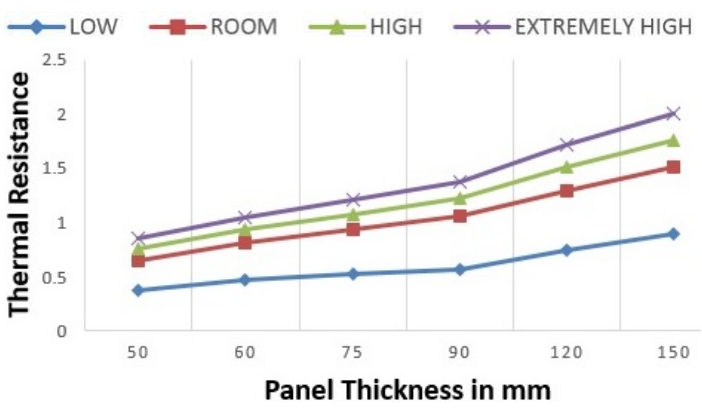

Fig 5 Thermal resistance (in $\mathrm{m}^{2} . \mathrm{K} / \mathrm{W}$ ) of sandwich panel of various thickness at various temperature

\subsection{Measurement of Steady State Temperature Gradient}

Fig 6 to Fig 10 show the steady state temperature graphs for panels of selected thickness at selected temperature range. The nature to the graph is similar for every thickness at every temperature range. Only difference is the temperature gradient value. Panel of low thickness has low temperature gradient whereas panel of greater thickness has higher temperature gradient. Also, for same thickness of sample, higher source temperature has shown higher temperature gradient.

The value of temperature gradient $\Delta \mathrm{T}$ is obtained from observation, and the value of thickness $L$ is measured from vernier calipers. Heat transfer rate is measured from the digital wattmeter. Electrical power measurement shown by the wattmeter is equivalent to heat energy as resistive heater with hundred percent heat efficiency is used.

Consider $90 \mathrm{~mm}$ sandwich panel is experimented with extreme source temperature 92.1 degree centigrade. Temperature gradient obtained is 71.1 degree centigrade. Heat transfer rate is $20 \mathrm{~W}$ and area is $0.0377 \mathrm{~m}^{2}$.

Using the above data we obtain

$\mathrm{k}=\frac{\mathrm{Q} \times \mathrm{L}}{\mathrm{AX \Delta T}}$

Here, $\mathrm{k}, \mathrm{U}$ and $\mathrm{R}$ are the values of Thermal conductivity, Overall Heat Transfer Coefficient and Thermal Resistance of $90 \mathrm{~mm}$ sandwich panel. Fig 7 shows the plot between temperature of source, Tin and cold surface temperature Tout with real time values. The graph is used to determine the temperature gradient.

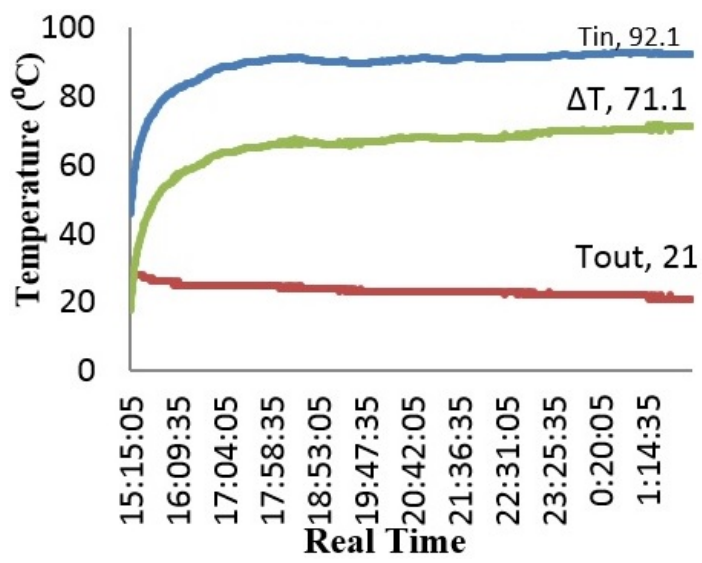

Fig 6 Temperature graph of $120 \mathrm{~mm}$ sandwich panel at high temperature

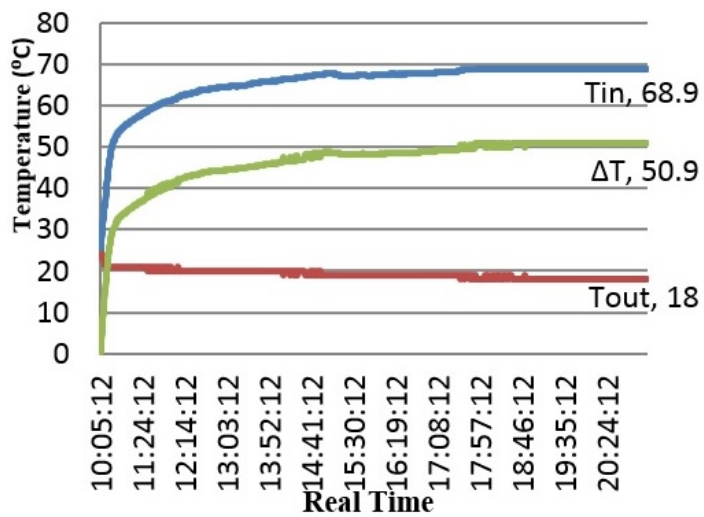

Fig 7 Temperature graph of $90 \mathrm{~mm}$ panel at extreme temperature

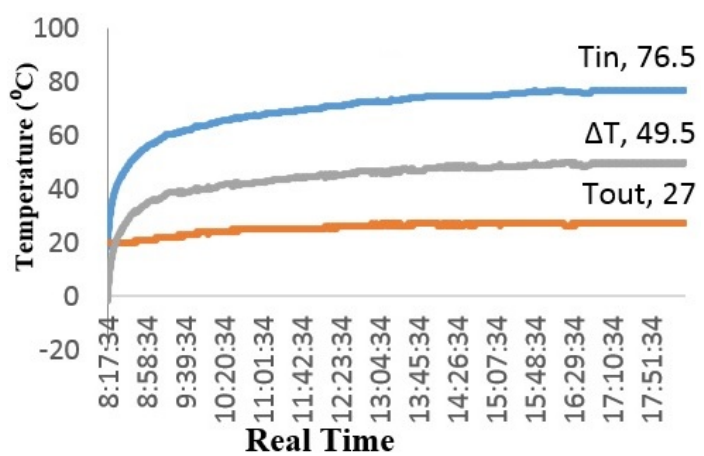

Fig 8 Temperature graph of $50 \mathrm{~mm}$ sandwich panel at extreme temperature 


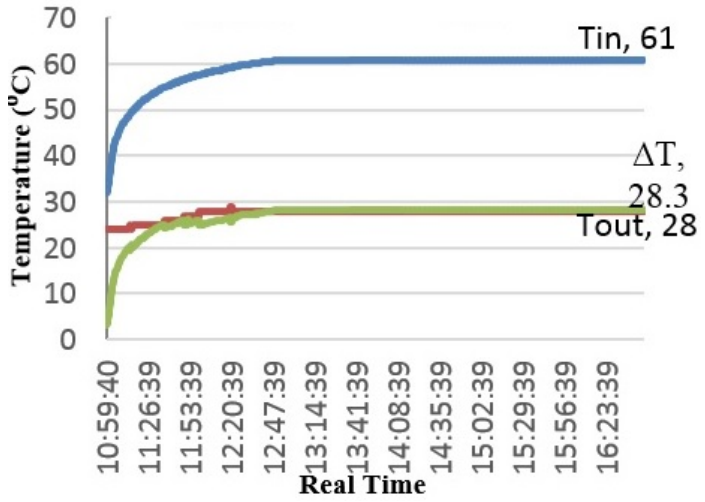

Fig 9 Temperature graph of $50 \mathrm{~mm}$ sandwich panel at high temperature

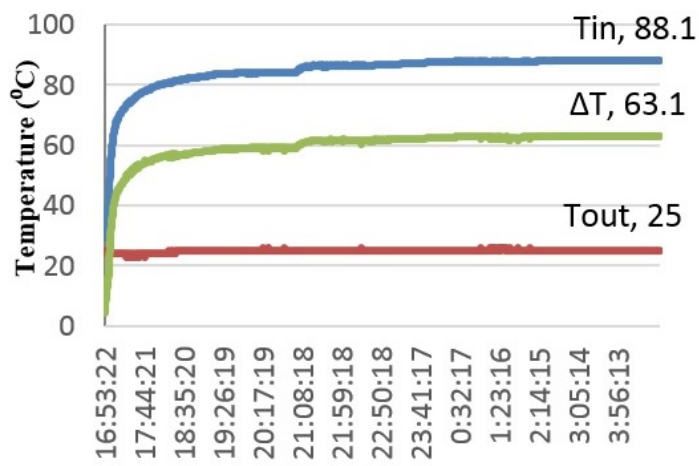

Real Time

Fig 10 Temperature graph of $60 \mathrm{~mm}$ sandwich panel at extreme temperature

From the observation, $\Delta \mathrm{T}=71.1^{\circ} \mathrm{C}$ for $90 \mathrm{~mm}$ sandwich panel at extreme temperature which corresponds to thermal conductivity of 0.58 $\mathrm{W} / \mathrm{m} . \mathrm{K}$, Overall heat transfer of $6.54 \mathrm{~W} / \mathrm{m}^{2} . \mathrm{K}$ and thermal resistance of $0.15 \mathrm{~m}^{2} . \mathrm{K} / \mathrm{W}$. From the observed values of $\mathrm{k}$, it can be concluded that the thermal conductivity of $90 \mathrm{~mm}$ panel is approximately 3 times less than that of common brick at similar temperature.

\section{Conclusion}

Thermal conductivity of EPS based lightweight concrete sandwich panel at room temperature is found to be $0.14 \mathrm{~W} /(\mathrm{m} . \mathrm{K})$ which is nearly three times less than that of common building brick. Thermal conductivity varies, however, according to the significant change in source temperature. At extreme temperature it may reach up to 0.65 $\mathrm{W} /(\mathrm{m} . \mathrm{K})$. Thermal resistance of $90 \mathrm{~mm}$ panel is found nearly $1 \mathrm{~m}^{2} . \mathrm{K} / \mathrm{W}$ at room temperature, which quite desires insulation property in building materials in many situations. It can be said that from thermal insulation point of view, EPS based lightweight concrete sandwich panel is much better than common brick for building partition walls.

\section{Acknowledgement}

The author would like to express his gratitude to International Green Developers Nepal Pvt. Ltd. for providing all kinds of support.

\section{References}

[1] Braz, J. (2012). Human Thermal Comfort: An Irreversibility based approach emulating empirical clothed-body correlations and the conceptual energy balance equation. Soc. Mech. Sci. \& Eng. , 4.

[2] Ede, A. N., \& Ogundiran, A. (2014). Thermal Behaviour and Admissible Compressive Strength of Expanded Polystyrene Wall Panels of Varying Thickness. Current Trends in Technology and Science, 110-117.

[3] Koju, S. M. (2015). Thermal Behaviour Study of EPS based Lightweight Concrete Panel and Its Comparison with Common Brick. Pulchowk: Institute Of Engineering, Pulchow Campus.

[4] Leila, R., \& Nacerddine, D. (2013). Influence of Thermal Conductivity On Energy Comsumption of Building. International Journal of Engineering Research \& Technology.

[5] Ning, L., \& Bing, C. (2014). Experimental Study Of The Influence of EPS Particle Size on Mechanical Properties of EPS Lightweight Concrete. Construction and Building Materials 68, 227-232.

[6] O'Connell, J. P. (2005). Thermodynamics: Fundamentals for Applications. Cambridge: Cambridge University Press.

[7] Oluwole, O., Joshua, J., \& Nwagwo, H. (2012). Finite Element Modeling of Low Heat Conducting Building Bricks. Journal of MInerals and Materials Characterization and Engineering, 800-806.

[8] Panjehpour, M. (2014). Evaluation of Structural Insulated Wall Panels Behaviour Using Various Substituted Materials. Journal of Civil Engineering and Architecture, 138-142.

[9] SaitSoylemez, M. (1998). On the Effective Thermal Conductivity of Building Bricks. Building and Environment. 